\title{
Prevention through parent training: Making more of a difference
}

\author{
Peter Stanley \\ Department of Human Development and Counselling, The University of Waikato. \\ Lesley Stanley \\ Special Education Early Intervention Team, Bay of Plenty East.
}

\begin{abstract}
Responding to serious behaviour problems requires new practice answers and emphases. Best practice principles and a developmental perspective indicate that the family should be the focus of preventative work. The Incredible Years parent training series is described as an important example of an empirically-supported programme that is presently being used in Tauranga and elsewhere in New Zealand. Impediments to prevention efforts are discussed and arguments are made regarding the relevance and significance of preventative strategies.
\end{abstract}

\section{KEYWORDS:}

Behaviour problems, prevention, early intervention, parent training, family involvement.

\section{INTRODUCTION}

Children and youth with serious behaviour problems, such as young people who are persistently disruptive, noncompliant and antisocial, represent significant challenges for health, welfare and education agencies. The sources of frustration include the complexity, intensity and the antagonistic nature of the presenting problems, the inability to access relevant support for clients, and the lack of interventions that make important and lasting differences. These issues are likely to be further compounded by a seemingly inexhaustible supply of new cases.

The Pychologists, Social Workers, Teachers and Special Educators who work with young people with problems are at the butt of social change. As the connections and coherence among social institutions such as schools, families, churches and neighbourhoods have diminished, so too has the capacity of parents to effectively monitor, protect and socialise their children (Reid \& Eddy, 1997; Rich, 1999). New problem behaviours have emerged, including unprotected sex, drug abuse, violence and depression to replace the "old morbidities" of nutritional deficits and health issues (Dryfoos, 1994). It is also likely that aggression in children is escalating and is being exhibited earlier (Campbell, 1990; Webster-Stratton, 1991). In addition, behavior problems seem more disturbing, and the outcomes appear more destructive (Walker, Zella, Close, Webber \& Gresham, 1999).

\section{PRACTICE PRINCIPLES FOR THE PRESENT AGE}

Professional practice needs to acknowledge the new realities and to programme accordingly. There are some realisations that should be given special prominence in a contemporary perspective. Firstly, behaviour problems in childhood must always be given serious professional consideration. Capaldi, DeGarmo, Patterson, and Forgatch (2002) comment that it is hard to overemphasise the importance of childhood conduct issues for maladjustment in men, and the consequences are also profound for their intimate partners and for the next generation of children. The Paediatricians' old rule, that most children's issues are just passing phases, is no longer relevant in these more perilous times (Reid \& Eddy, 2002).

A second guiding principle concerns the centrality of the primary caregiving relationship to child outcomes. Luthar and Zelazo (2003) conclude a review of resilience research with the assertion that the importance of supportive adults in the lives of children has been repeatedly and consistently demonstrated. Again with respect to resilience, Masten (2001) and Masten and Coatsworth (1998) say that young people who achieve competence in the midst of adversity have done nothing more, or less, than access the powerful processes of normal adaptive development, and caring prosocial parenting is a crucial context for this "ordinary magic" to occur.

The third matter is the amount of effort that is required to bring about sustained change for young people who are at risk for negative life events and outcomes. Programmes need to be powerful and direct, and to match the presenting problem (Walker et al., 1999). A continuum of behavioural supports should be available, and for school-aged children and youth, multicomponent strategies are often needed to accord with the multicausal, multiple settings and intransigent qualities of problem behaviour (Hawkins, Catalano, \& Miller, 1992; Reid, 1993). A number of commentators argue for continuing interventions for at-risk children and families, which contrast with conventional "one shot" approaches (Dishion, Andrews, Cavanagh, \& Soberman, 1996; Kazdin, 1997a; Zigler, Taussig, \& Black, 1992).

Endorsement of empirically-supported programmes is another criterion for contemporary professional practice. Quite simply, all intervention options are not of equal merit and it is preferable to make choices in relation to reliable and verifiable data (Kauffman, 1999a). It is a fact that most psychological treatments for child problem behaviours have not been evaluated scientifically but there are some promising approaches to conduct difficulties. These include parent training, functional family therapy, multisystemic therapy and cognitive problem-solving skills training (Kazdin, 1997a). It has been suggested that research-based practice

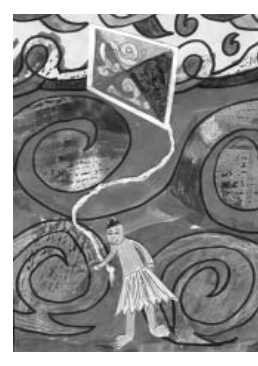


is synonymous with accountability and it does not detract from the importance of individual professional skills and competence (Chambless \& Olledick, 2001; Evans, 1997). Empirically-supported programmes assist in "narrowing choices, maximizing results, and minimising harm" (Sugai, 2003, p. 217).

The fifth and final response component is preventative strategies for serious behaviour problems in children and youth. Prevention has been described as possibly the most important lesson to be learned from the history of work with emotional and behavioural issues (Whelan, invited commentary, in Kauffman, 2001) and the writers on this subject use graphic language to emphasise its importance Traditional responses to individuals with established behaviour problems are depicted as backloading (Forness, 2003) and a casualty-repair reaction (Cowen, Hightower, Pedro-Carroll, Work, Wyman \& Haffey, 1996) to a pipeline packed with young people experiencing traumatic events and outcomes (Walker \& Sprague, 2002). Without doubt, preventative approaches are the most practical way to proceed as the pyramid of numbers inevitably promises less and less to increasing numbers of children and youth who are problems to themselves and to others.

\section{A DEVELOPMENTAL PERSPECTIVE}

The significance of childhood problems and parenting, and the need for appropriate programmes and prevention are given substantial support by the numerous studies that have traced the development of conduct problems and antisocial behaviour. As Reid (1993) says, there has been a lot of success in mapping these behaviours from infancy to adolescence. The lifespan view is exemplified in the discipline of developmental psychopathology (Cicchetti \& Cohen, 1995) and in the organisational model of development (Yates, Egeland, \& Sroufe, 2003). In these approaches, both adaptive and maladaptive outcomes are the products of events, or antecedents, which build on each other and have a cumulative effect. However, the direction of development, or trajectory, is always probabilistic rather than certain, as young people can make and be affected by unanticipated choices (Sameroff, 1995).

There are strong links between early indications of antisocial behaviour and subsequent manifestations. For instance, Broidy et al., (2003), report an international cross-site analysis that includes both the Christchurch Health and Development Study and the Dunedin Multidisciplinary Health and Development Study, which shows chronic physical aggression in childhood to be a distinct predictor of violent and nonviolent delinquency in adolescence for males. Indeed, the consistencies that have been found for early indices are of such magnitude as to prompt some commentators to describe antisocial tendencies in strongly deterministic terms. Walker et al. (1999) say that an established antisocial behaviour pattern is like an immune disorder, which makes the person susceptible to other diseases, and Kazdin (1987) compares conduct disorder to diabetes, a chronic complaint to be managed rather than cured.
There are now repeated calls in the literature for research on the mechanisms and processes that take children along the pathways to competence and maladjustment (Doll \& Lyon, 1998; Luthar, Cicchetti, \& Becker, 2000). The elucidation of these operations has obvious importance for prevention and it signals a much more sophisticated and useful approach than is afforded by the current listings of risk and protective factors. A major development with respect to conduct issues and antisocial behaviour has been the uncovering of coercive family processes as an explanatory device. This is the work of Gerald Patterson and colleagues at the Oregon Social Learning Centre, (http://www.oslc.org) and it accounts for noncompliance and consequent maladjustment in the aversive exchanges of child and caregiver. The parent makes demands of the child who responds with sufficient negativity such as whining, yelling, temper tantrums and physical attacks, for the caregiver to back down and back away. The young person's oppositional responses, which are initially negatively reinforced by parents, are subsequently shaped and confirmed by teachers, peers, and others (Patterson, DeBaryshe, \& Ramsey, 1989; Patterson, Reid, \& Dishion, 1992; Reid, Patterson, \& Snyder, 2002).

Kauffman (2001) observes that the homeliness of the coercion mechanism belies its importance. The significance of family processes is shown in the fact that poor parental discipline is an even better predictor of later antisocial behaviour than is an early childhood history of behavioural difficulties (Reid, 1993). The pivotal role of parenting is also apparent when the relative effects of risk factors are compared, and in this regard it is noteworthy that parents can continue to raise competent children while burdened with depression, engaging with illicit substances and living in poverty. The Oregon model hypothesises that these less direct, or distal, influences are mediated through the microsocial events that occur between children and adults (Reid \& Eddy, 2002).

\section{FAMILY-FOCUSED INTERVENTIONS}

The above principles for practice when combined with the developmental perspective on antisocial behaviour, strongly suggest that the family should be the prime focus of professional efforts. For most children, the family is the first and most enduring proximal, or direct, socialising influence. As a setting, it has a special capacity to extend its protective influence into other social contexts such as the peer group and the school (Reid \& Eddy, 1997). In an early statement, Gerald Patterson patently defined the power that parents possess.

Only a parent loves the child enough to go through the hundreds of trials in which the child learns when he can, or cannot, use pain control techniques. Later, his wife or his psychoanalyst may give him love and support equal to that given by his mother, but they cannot teach him at a molecular level those subtle skills that he should have learned prior to age six or seven. Parental power, relative to a preschool child, is simply overwhelming. Social workers, or friends, or therapists do not possess an equivalent means 
for punishing adolescent and adult deviant behaviour. They may help the adolescent to feel better about his antisocial behaviour but they cannot stop the behaviour in the sense that a parent can (Patterson, 1982, pp. 220-221).

It is impossible to begin professional work with parents too soon. However, in practical terms, infancy, early childhood and when children begin school, are optimal times for intervention. The appeal of infancy and early childhood is that the family often has exclusive influence during these periods, although this is changing with the increasing use by parents of childcare facilities. The first year of primary school is also a good time because it is possible to make reasonably accurate predictions about the likelihood of continuing difficulties at this point while still being able to enlist the involvement and support of parents and teachers for programmes (Coie, 1996; Stanley, 2003a). Intervening at a young age avoids the additional complications and continuing distress of well-established problems. Nevertheless, family-focused work should be considered for a young person at any stage who is evidencing elevated levels of oppositional behaviour (Stanley, 2001).

Placing families at the centre of professional activities does not mean that individual child factors such as temperament and health or other social contexts, such as school and neighbourhood, are ignored. An issue with child attributes is that they are frequently both parts and products of transactional developmental processes (as exemplified by coercion in the Oregon model) and it can be difficult to distinguish them from family variables (Luthar \& Zelazo, 2003). As well, we need to be wary of attributing causative status to characteristics such as anger, low self-esteem and depression in antisocial young people. These are often the concomitants and consequences of ineffectual and aversive parenting, and programmes that attempt lasting change via these aspects are inevitably destined to fail (Reid \& Eddy, 2002).

Extrafamilial risk and protective factors are typically significant to professional responses for children and youth exhibiting persistent disruption, noncompliance and antisocial behaviour. An intervention that ignores these conditions can be fatally weakened but workers can also appear to have an excessively narrow purview that could effectively result in the "individualisation of social problems" (Smale et al. in Jack, 2001, p. 68). Yates et al. (2003) reflect on the multiple challenges that can exist in caregivers' lives and conclude that "comprehensive and successful intervention efforts aimed at disadvantaged youth and their families should target the parent-child attachment relationship in the context of a family-focused, multipronged, interdisciplinary programme" (p. 256).

\section{THE INCREDIBLE YEARS TRAINING PROGRAMMES}

The Incredible Years series of parent, teacher and child group-training programmes developed by Webster-Stratton and her colleagues (e.g. Webster-Stratton \& Herbert, 1994; http://www. incredibleyears.com) is an empirically-supported, family-focused intervention system that has been widely adopted by youth agencies in the US and also employed in Canada, Scandinavia, Holland and the UK (McHale, 2004), and is now being used in New Zealand in some districts by services such as Special Education (Ministry of Education, 2004). The purpose of the programmes is to prevent delinquency, drug abuse and violence. The short-term objectives of the series are to reduce conduct problems and promote social, emotional and academic abilities in children, and to facilitate parental and teacher competence. The long-range goals are to provide a cost-effective, community-based, prevention programme while also responding to young children with early onset conduct problems (Webster-Stratton, 2000).

Incredible Years is based on social learning principles and it uses a collaborative and consultative training model, which enables and empowers participants to formulate solutions to child management issues that will work for their unique family and classroom situation (Webster-Stratton, 1998). The training involves participant analysis and discussion of microsocial events that occur in relationships with children as seen on videos of adult-child interactions and experienced through role plays, group problem solving and homework activities. There are in fact three parenting programmes Basic, Advance and Supporting Your Child's Education that allow for a "one shot" response or ongoing interventions. Additionally, parent training can be complemented by the child programme (known as the Dina Dinosaur Social Skills and Problem-Solving Curriculum) and/or the teacher programme, when a multi-element involvement is required.

In subject matter, the Basic Parent Training Programme covers play, praise and rewards, effective limit setting, and handling misbehaviour. This course can focus on early childhood (ages 2-7 years) or the early school age (5-12 years). For the latter group, more time is spent on problemsolving, monitoring, logical consequences and some special problems, such as lying, stealing and hitting. The Advance Parent Programme (focusing on children aged 4-10 years) reviews material from the Basic Programme and stresses the application of communication and problem-solving skills to relationships, both with adults and with children. The Supporting Your Child's Education Programme (for ages 5-12 years) requires completion of the Basic Programme. It addresses promoting the child's self-confidence, fostering good learning habits, dealing with discouragement, participating in children's homework and using parent/ teacher conferences to advocate for the child.

Webster-Stratton and others (Spitzer, Webster-Stratton \& Hollinsworth, 1991; Webster-Stratton \& Herbert, 1994) have identified the stages that parents pass through on the journey to becoming increasingly competent caregivers. Firstly, parents must acknowledge that the family has a child management issue. In the second stage, as they acquire new strategies, caregivers experience feelings of despair and hope. A period of adjustment follows as it is realised that there are no magical solutions. In phase four, or "making the shoe fit", the training principles are adapted to individual 
circumstance. In the final stage, parents begin to show effective coping and greater acceptance of the child, and they realise that they have ongoing needs to obtain support and to refresh. This analysis is of practical assistance to trainers. It also offers exciting directions for exploring the interplay between parent ideas and the process of effective therapy (Johnston, 1996).

The Incredible Years parent, teacher and child training series have been rated by the US Department of Justice as an exemplary "best practices" programme. To achieve this status, the programmes were rated by independent reviewers on the following 14 dimensions:

- theory

- fidelity of interventions

- sampling strategy and implementation

- attrition

- measures

- missing data

- data collection

- analysis

- other plausible threats to validity (excluding attrition)

- replications

- dissemination capability

- cultural and age appropriateness

- integrity

- utility.

The series has been endorsed by the American Psychological Association as a well-established intervention for conduct problems in children. Randomised control group studies have shown moderate to substantial effects on the parenting practices of socioeconomically-disadvantaged mothers with mental health problems (Baydar, Reid, \& Webster-Stratton, 2003). Positive long-term effects have also been demonstrated across cultures and the programmes have proven to be of high acceptability to all groups (Reid, Webster-Stratton, \& Beauchaine, 2001). A local evaluation of the parent training is now available (Lees, 2003) and further assessment is planned by the Medical School, University of Auckland (Bleckmann, personal communication, April, 2004).

The formal endorsements of the Incredible Years are complemented by parent testimonies.

For me personally I have learned that I am not the only one with a child that does not fit in. I am not the only one that has felt that the world is against me and my child. My child's behaviour is not unique, not a result of bad parenting and not personal. I do not have the world's most difficult child ... This course provides an essential 'tool box' of techniques that allows both the user and recipient to better appreciate and communicate with one another in a safe and healthy environment, geared for growth. It is truly a course for those who want to invest in their child and family. (Name withheld, personal communication, September 16, 2004.)
Lesley Stanley is an experienced parent trainer and involvement with the Incredible Years has shown that it is a refuelling and energising experience for professionals and, in part, this is because it promotes collegial support with the training delivered in pairs, and it is a practical response to high caseloads. The principal satisfaction, however, is in having methods that work and in being able to make more of a difference. Additionally, direct experience indicates that the programmes establish professional and parent partnerships that can be returned to when difficulties reoccur. Moreover, it has been demonstrated that community agencies can work together and engage with families who have multiple problems and cross categorical service boundaries. The next step for service providers could be to link training programmes to screening and identification procedures and to address problem behaviours systematically, as well as effectively (Stanley, Rodeka, \& Laurence, 2000). Lastly, to ensure that these various benefits and possibilities continue to be available, it is essential that facilitator training is readily accessible and treatment fidelity is rigorously maintained (Webster-Stratton, n.d.).

\section{THE PREVENTION OPTION}

Preventing and delimiting behaviour problems through parent training programmes, such as the Incredible Years series, has a self-evident logic and it can be difficult to understand why it is not the foremost intervention presently in use by education, health and welfare services. However, there is a comprehensive array of philosophical and practical ploys that are remarkably effective at stymieing preventative efforts. Kauffman (1999b) has catalogued the various obstructive gambits that are used by both the public and by professionals and they include avoidances, misinterpretations, and protests. These impediments to prevention can take an escalating toll on effective casework. In a review of various interventions, Church (2003) says that the best programmes have been shown to work for seventy-five to eighty percent of preschool children, sixty-five to seventy percent of children aged 5-7, forty-five to fifty percent of children aged 8-12 and a "small fraction" of adolescents who exhibit antisocial behaviour. Furthermore, Church estimates that the monetary costs of successful interventions increases from $\$ 5,000$ for a five-year-old to $\$ 60,000$ for a 15 -year-old.

How problem behaviours in children are conceptualised is a major complicating issue for prevention. Family-centred professional work is avowedly ecological and it tends to align with systems theory, where causality is understood in terms of "simultaneously occurring, mutually influential, and interrelated phenomena" (Henggeler, Schoenwald, Borduin, Rowland, \& Cunningham, 1998, p.11). By contrast, conventional agency approaches incline towards attributing fault to distinct and static entities, whether within the child or the environment, and categorising accordingly, such as conduct disorder and child protection. Service delivery based on these notions of discreet cause is professionally limited because it is inevitably reactive and cannot account for 
positive developmental outcomes (Glantz \& Sloboda, 1999). For clients it is personally limiting, because the responses are inherently pathologising and stigmatising. By contrast, dynamic and inclusive models, which are committed to competence enhancement, more readily acknowledge and respect what clients bring to the helping process.

The idea that children and families are influenced by, and respond to, a myriad of forces is a major departure from the linear logic of categorisation and labelling. It is also a response to the charge of "family-blaming" that is sometimes levelled at parent training. Families are typically enmeshed in a host of dynamic and reciprocal associations, which cross both social settings and time, and if fault is to be found it should be in a system of relationships rather than in people. As indicated, it is the categorical approaches that allocate blame and in the case of psychiatric diagnoses, such as Attention Deficit/Hyperactivity Disorder, that can attribute the problem to the child while simultaneously absolving the parents (Read, Seymour, \& Mosher, 2004). Arguably, neither blaming nor absolving, which are both judgements, should be a part of an informed and rational approach to professional work.

A second complicating matter for preventative efforts concerns the place of science in the remediation of behavioural problems. Empirically-supported programmes have been both a target and victim of postmodernism (Kauffman, 2003; Nelson, 2003; Sasso, 2003) but perhaps more significantly they may simply not be understood by important occupational groups that work with children and youth. The education profession in particular, according to Simpson (1999), readily accepts methods that are not validated or empirically based. The use by our schools of a succession of unproven drug education packages gives some support to this view (Stanley, 2003b). As well, there may be a cultural component in the aversion to packaged programmes. The Kiwi approach is do-it-yourself and to display no. 8 fencing-wire improvisation (King, 2003), rather than be told what to do.

We should never lose sight of the enormous personal, social and economic costs associated with conduct difficulties and antisocial behaviour. For the individuals who complete the course, from early coercive exchanges to adult criminality, there awaits unemployment, failed relationships, substance abuse, institutionalisation and a "marginal existence characterised by a constant stream of crises" (Patterson et al., 1992, p.14). Each of the negative antecedents of this adult status is a significant social problem in New Zealand in its own right, and the familiar list includes child maltreatment, bullying, school failure, sexually transmitted diseases, teenage pregnancy, depression, suicide, and motor vehicle accidents.

The advent of proven parenting programmes might be likened to the discovery of antibiotics in medicine. Now there is an intervention that can reliably interrupt a maladaptive developmental trajectory and simultaneously build capacities in the caregiver and the child. Potentially, parent training is the therapeutic gift that goes on giving as the siblings of the target child benefit (Kazdin, 1997b) and the intergenerational cycle of dysfunction and disadvantage is broken. There is a marked contrast between this approach and many contemporary provisions. According to Church (2003), none of the following interventions has been shown to have long-term beneficial effects for the antisocial adolescent: probation and parole, individual counselling, group counselling, family counselling, vocational counselling, activity centres, alternative education programmes, mentoring, outdoor programmes or deterrence programmes such as boot camps and "scared straight".

In the future, and in response to new societal realities, services for young people are probably going to be increasingly integrated, consumer driven, cost conscious, and outcome oriented (Illback, 1997). The new generation of parenting programmes, including the Incredible Years, is representative of this trend while meeting injunctions for interventions to be grounded in solid theory, based on replicable empirical evidence, and referenced to the creation of best practices (Walker et al., 1999). For practitioners, these demands for accountable, relevant, and useful services may effectively translate into a journey similar to that experienced by caregivers during parent training (Spitzer et al., 1991; Webster-Stratton \& Herbert, 1994). There will be phases of acknowledgement and adjustment, and other stages when programmes are individualised and emerging coping strategies are supported. The very important lesson associated with this difficult and taxing process is that it is the characteristics of the intervention, and not of the client, that determine the outcome (Webster-Stratton, 1998).

\section{REFERENCES}

Baydar, N., Reid, M. J., \& Webster-Stratton, C. (2003). The role of mental health factors and programme engagement in the effectiveness of a preventive parenting programme for Head Start mothers. Child Development, 74(5), 1433-1453.

Broidy, L. M., Nagin, D. S., Tremblay, R. E., Bates, J. E., Brame, B., Dodge, K. A., Fergusson, D., Horwood, J. L., Loeber, R., Laird, R., Lynam, D. R., Moffitt, T. E., Pettit, G. S., \& Vitaro, F. (2003). Developmental trajectories of childhood disruptive behaviors and adolescent delinquency: A six-site, crossnational study. Developmental Psychology, 39(2), 222-245.

Campbell, S. B. (1990). Behavior problems in preschool children: Clinical and developmental issues. New York: Guilford.

Capaldi, D., DeGarmo, D., Patterson, G. R., \& Forgatch, M. (2002). Contextual risk across the early life span and association with antisocial behavior. In J. B. Reid,

G. R. Patterson, \&J. Snyder (Eds.), Antisocial behavior in children and adolescents. A developmental analysis and model for intervention (pp. 123-145). Washington, DC: APA Books.

Chambless, D. L., \& Ollendick, T. H. (2001). Empirically supported psychological interventions: Controversies and evidence. Annual Review of Psychology, 52, 685-716. 
Church, J. (2003). The definition, diagnosis and treatment of children and youth with severe behaviour difficulties: A review of research. Wellington: Ministry of Education.

Cicchetti, D., \& Cohen, D. J. (1995). Perspectives on developmental psychopathology. In D. Cicchetti \& D. J. Cohen (Eds.), Developmental psychopathology. Volume 1: Theory and methods (pp. 3-20). New York: Wiley.

Coie, J. D. (1996). Prevention of violence and antisocial behavior. In R. D. Peters \& R. J. McMahon (Eds.), Preventing childhood disorders, substance abuse, and delinquency (pp. 1-18). Thousand Oaks, CA: Sage.

Cowen, E. L., Hightower, A. D., Pedro-Carroll, J. L., Work, W. C., Wyman, P. A., \& Haffey, W. G. (1996). School-based prevention for children at-risk: The Primary Mental Health Project. Washington, DC: APA Books.

Dishion, T. J., Andrews, D. W., Kavanagh, K., \& Soberman, L. H. (1996). Preventive interventions for high-risk youth: The Adolescent Transitions Programme. In R. D. Peters \& R. J. McMahon (Eds.), Preventing childhood disorders, substance abuse and delinquency (pp. 184-214). Thousand Oaks, CA: Sage.

Doll, B., \& Lyon, M. A. (1998). Risk and resilience: Implications for the delivery of educational and mental health services in schools. School Psychology Review, 27(3), 348-363.

Dryfoos, J. G. (1994). Full service schools. San Francisco: Jossey Bass.

Evans, I. M. (1997). The role of research in psychological practice: Implications of the scientist-practitioner model. In H. Love \& W. Whittaker (Eds.), Practice issues for clinical and applied psychologists in NZPSS.

Forness, S. R. (2003). Parting reflections on education of children with emotional or behavioral disorders. Behavioral Disorders, 28(3), 198-201.

Glantz, M. D., \& Sloboda, Z. (1999). Analysis and reconceptualization of resilience. In M. D. Glantz \& J. L. Johnson (Eds.), Resilience and development: Positive life adaptations (pp. 109-126). New York: Kluwer.

Hawkins, J. D., Catalano, R. F., \& Miller, J. Y. (1992). Risk and protective factors for alcohol and other drug problems in adolescence and early adulthood: Implications for substance abuse prevention. Psychological Bulletin, 112(1), 64-105.

Henggeler, S. W., Schoenwald, S. K., Borduin, C. M., Rowland, M. D., \& Cunningham, P. B. (1998). Multisystemic treatment of antisocial behavior in children and adolescents. New York: Guilford.

Illback, R. J. (1997). Creating responsive systems of care: Professional and organisational challenges. In R. J. Illback, C. T. Cobb, \& H. M. Joseph (Eds.), Integrated services for children and families: Opportunities for psychological practice (281-301). Washington, DC: APA Books.
Jack, G. (2001). Ecological perspectives in assessing children and families. In J. Horwath (Ed.), The child's world. Assessing children in need (pp.53-74). London: Kingsley.

Johnston, C. (1996). Addressing parent cognitions in interventions with families of disruptive children. In K. Dobson \& K. Craig (Eds.), Advances in cognitive behavioral therapy (pp. 193-209). Thousand Oaks, CA: Sage.

Kauffman, J. M. (1999a). The role of science in behavioral disorders. Behavioral Disorders, 24(4), 265-272.

Kauffman, J. M. (1999b). How we prevent the prevention of emotional and behavioral disorders. Exceptional Children, 65(4), 448-468.

Kauffman, J. M. (2001). Characteristics of emotional and behavioral disorders of children and youth (7th ed.). Upper Saddle River, NJ: Merrill.

Kauffman, J. M. (2003). Reflections on the field. Behavioral Disorders, 28(3), 205-208.

Kazdin, A. E. (1987). Conduct disorders in childhood and adolescence. Newbury Park, CA: Sage.

Kazdin, A. E. (1997a). Practitioner review: Psychological treatments for conduct disorder in children. Journal of Child Psychology and Psychiatry, 38(2), 161-178.

Kazdin, A. E. (1997b). Parent management training: Evidence, outcomes, and issues. Journal of the American Academy of Child and Adolescent Psychiatry, 36(10), 1349-1356.

King, M. (2003). The Penguin history of New Zealand. Auckland: Penguin.

Lees, D. G. (2003). Parent management training for the families of children diagnosed with attention deficit hyperactivity disorder. Unpublished Master's thesis, Massey University, Palmerston North.

Luthar, S. S., Cicchetti, D., \& Becker, B. (2000). The construct of resilience: A critical evaluation and guidelines for future work. Child Development, 71(3), 543-562.

Luthar, S. S., \& Zelazo, L. B. (2003). Research on resilience: An integrative review. In S. S. Luthar (Ed.), Resilience and vulnerability: Adaptation in the context of childhood adversities (pp. 510-549). Cambridge: Cambridge University Press.

McHale, L. (2004, Winter). CHDD research affiliate studies prevention of long-term behavior problems in Head Start preschoolers. CHDD Outlook [Online]. Retrieved May 10, 2004, from http://www. incredibleyears.com/.

Masten, A S. (2001). Ordinary magic. Resilience processes in development. American Psychologist, 56(3), 227-238.

Masten, A. S., \& Coatsworth, J. D. (1998). The development of competence in favourable and unfavourable environments: Lessons from research on successful children. American Psychologist, 53(2), 205-220. 
Ministry of Education. (2004). Professional practice in special education. Wellington: Author.

Nelson, C. M. (2003). Through a glass darkly: Reflections on our field and its future. Behavioral Disorders, 28(3), 212-216.

Patterson, G. R. (1982). A social learning approach, Volume 3: Coercive family process. Eugene, OR: Castalia.

Patterson, G. R., DeBaryshe, B. D., \& Ramsey, E. (1989). A developmental perspective on antisocial behavior. American Psychologist, 44(2), 329-335.

Patterson, G. R., Reid, J. B., \& Dishion, T. J. (1992). A social interactional approach, Volume 4: Antisocial boys. Eugene, OR: Castalia.

Read, J., Seymour, F., \& Mosher, L. R. (2004). Unhappy families. In J. Read, L. R. Mosher, \& R. P. Bentall (Eds.), Models of madness. Psychological, social and biological approaches to schizophrenia (pp.253-268). Hove, UK; Brunner.

Reid, J. B. (1993). Prevention of conduct disorder before and after school entry: Relating interventions to developmental findings. Development and Psychopathology, 5, 243-262.

Reid, J. B., \& Eddy, J. M. (1997). The prevention of antisocial behavior: Some considerations in the search for effective interventions. In D. M. Stoff, J. Breiling, \& J. D. Maser (Eds.), Handbook of antisocial behavior (343-356). New York: Wiley.

Reid, J. B., \& Eddy, J. M. (2002). Interventions for antisocial behavior: Overview. In J. B. Reid, G. R. Patterson, \& J. Snyder (Eds.), Antisocial behavior in children and adolescents. A developmental analysis and model for intervention (195-201). Washington, DC: APA Book.

Reid, J. B., Patterson, G. R., \& Snyder, J. (2002). Antisocial behavior in children and adolescents: A developmental analysis and model for intervention. Washington, DC: APA Books.

Reid, M. J., Webster-Stratton, C., \& Beauchaine, T. (2001). Parent training in Head Start: A comparison of programme response among African American, Asian American, Caucasian, and Hispanic mothers. Prevention Science, 2(4), 209-227.

Rich, D. (1999). Building relationships for learning. In A. J. Reynolds, H. J. Walberg, \& R. P. Weissberg (Eds.), Promoting positive outcomes (73-94). Washington, DC: CWLA Press.

Sameroff, A.J. (1995). General systems theories and developmental psychopathology. In D. Cicchetti \& D. J. Cohen (Eds.), Developmental psychopathology. Theory and methods (Vol. 1, pp.659-695). New York: Wiley.

Sasso, G. M. (2003). An examined life: A response to James Kauffman's reflections on the field. Behavioral Disorders 28(3), 25-32.
Simpson, R. L. (1999). Children and youth with emotional and behavioral disorders: A concerned look at the present and a hopeful eye for the future. Behavioral Disorders, 24(4), 284-292

Spitzer, A., Webster-Stratton, C., \& Hollinsworth, T. (1991). Coping with conduct-problem children: Parents gaining knowledge and control. Journal of Clinical Child Psychology, 20(4), 413-427.

Stanley, P. (2001). Parent training: An intervention not to be ignored. Kairaranga. The Journal of New Zealand Resource Teachers of Learning and Behaviour, 2(2), 16-18.

Stanley, P. (2003a). Risk and resilience: Part 2, Applications. Kairaranga. The Journal of New Zealand Resource Teachers of Learning and Behaviour, 4(2), 25-32.

Stanley, P. (2003b). Drug education: A deceptively simple answer to a complex question. Teachers and Curriculum, 6, 69-73.

Stanley, P., Rodeka, P., \& Laurence, K. (2000). Guidelines for teachers for the identification of year 7 students at-risk for substance abuse and other problem behaviours. Porirua: Whatuora Research Centre, Specialist Education Services.

Sugai, G. M. (2003). Mike is right: Lessons learned from reflections. Behavioral Disorders, 28(3), 217-220.

Walker, H. M., Horner, R. H., Sugai, G., Bullis, M., Sprague, J. R., Bricker, D., \& Martin, J. (1996). Integrated approaches to preventing antisocial behavior patterns among school-age children and youth. Journal of Emotional and Behavioral Disorders, 4(2), 194-209.

Walker, H. M., \& Sprague, J. R. (2002). The path to school failure, delinquency, and violence: Causal factors and some potential solutions. Intervention in School and Clinic, 35(2), 67-73.

Walker, H. M., Zeller, R. W., Close, D. W., Webber, J., \& Gresham, F. (1999). The present unwrapped: Change and challenge in the field of behavioral disorders. Behavioral Disorders, 24(4), 293-304.

Webster-Stratton, C. (n.d.). Quality training, supervision, ongoing monitoring, and agency support: Key ingredients to implementing The Incredible Years programmes with fidelity. Retrieved May 10, 2004, from http://www. incredibleyears.com/.

Webster-Stratton, C. (1991). Annotation: Strategies for working with families of conduct-disordered children. British Journal of Child Psychiatry and Psychology 32(7), 1047-1062.

Webster-Stratton, C. (1998). Parent training with low-income families: Promoting parental engagement through a collaborative approach. In J. Lutzer (Ed.), Handbook of child abuse research and treatment (pp. 183-209). New York: Plenum. 
Webster-Stratton, C. (2000). The Incredible Years Training Series. Juvenile Justice Bulletin. Reprinted in C. WebsterStratton (2001), The Incredible Years: Parents, teachers, and children training series: Leader's guide (rev ed., pp. 1-23). Seattle, WA: Author.

Webster-Stratton, C., \& Herbert, M. (1994). Troubled familiesproblem children. Working with parents: A collaborative process. Chichester, UK: Wiley.

Yates, T. M., Egeland, B., \& Sroufe, L. A. (2003). Rethinking resilience: A developmental perspective. In S. S. Luthar (Ed.), Resilience and vulnerability: Adaptation in the context of childhood adversities (pp. 243-266). Cambridge: Cambridge University Press.

Zigler, E., Taussig, C., \& Black, K. (1992). Early childhood intervention: A promising preventative for juvenile delinquency. American Psychologist, 47(8), 997-1006.

\section{PROFILE OF AUTHORS}

Peter Stanley is a Senior Lecturer in the Department of Human Development and Counselling at The University of Waikato in Tauranga. He is also a Registered Psychologist who was previously employed by Specialist Education Services (SES). Peter's interest in the prevention of problem behaviours stems from experience working with students with challenging behaviour, and from previous career involvements as a Guidance Counsellor, primary and secondary school Teacher, Probation Officer and Police Constable.

Lesley Stanley is a Registered Psychologist and Lead Practitioner with the Special Education Early Intervention Team in Bay of Plenty East. In 2003, Lesley travelled to Sheffield to attend workshops for certification as a Parent Group Leader for the Incredible Years Parent Programme series and as a Child Group Leader. She has subsequently facilitated seven Basic Parent Training groups. She is also a member of the Incredible Years Guardian Group, which is an association of education, health and social service agencies in Tauranga that are offering the Webster-Stratton parent programmes. Lesley's interest in parent training goes back to the early 1980's when she first ran groups for caregivers seeking behaviour management strategies and support. 